Original Article

\title{
Pattern of Renal Diseases Among Children Admitted to Assiut University Children Hospital.
}

\author{
Ahmad Roshdy Ahmad',2, Ahlam Badawy Ali', and Aya Ahmed Khalifa' \\ 1- Pediatric Department, Faculty of Medicine, Assiut University, Egypt. \\ 2- Pediatric Department, College of Medicine, JUF, University, KSA.
}

\begin{abstract}
\section{Introduction}

The pattern of childhood renal diseases is different in developing countries in comparison to developed countries. Pediatric renal disease may be difficult to diagnose early as it may present only with mild symptoms._The aim of this study is to find out the pattern of renal diseases in children admitted at Assuit University Children Hospital over one year duration.
\end{abstract}

\section{Patients and methods}

This observational study was carried out on children and adolescents with age range from 1 day to 18 years who were admitted Assuit University Children Hospital over a period of one year from November 2016 to October 2017 data collected included symptoms, signs and investigation that aided in patients diagnosis.

\section{Results}

Renal diseases had constituted $1.15 \%$ of total number of patients admitted to pediatrics department in this duration. Out of 482 patients $29.7 \%$ were diagnosed as acute kidney injury (AKI) due to prerenal cause, $15.1 \%$ had glomerulonephritis (GN), $14.7 \%$ had nephrotic syndrome (NS), $14.1 \%$ had congenital anomalies of the kidney and urinary tract(CAKUT), $6.6 \%$ had urolithiasis, 5.6\% had hemolytic uremic syndrome(HUS), 5\% had tubular disorder,4.1\% urinary tract infection (UTI) not associated with renal disease, $2.7 \%$ had chronic kidney disease(CKD) due to unknown cause and finally diabetic nephropathy $(\mathrm{DN})$ was seen in $2.3 \%$ from totally diagnosed patients. The common presenting features were odema , oliguria and hematuria.

\section{Conclusion}

The most common renal disease was acute kidney injury due to prerenal cause.

\section{Keywords}

Acute ,kidney ,injury, Renal diseases, children glomerulonephritis

\section{Correspondence}

Aya Ahmed Khalifa Mohammed

Pediatrics Department Faculty of Medicine-Assiut University

Email: dr.ayaahmedkhlifa@gmail.com

\author{
geget : The Journal of the Egyptian Society of Pediatric Nephrology and Transplantation (ESPNT) \\ geget https://geget.journals.ekb.eg/ \\ Published by ESPNT http://espnt.net/ \\ Cohosted by Egyptian Knowledge Bank https://www.ekb.eg
}




\section{Introduction}

The pattern of renal diseases in children is different in developing countries in comparison to developed one . Pediatric renal disease may be difficult to diagnose early as it may present only with mild symptoms. During infancy and early childhood fever with unknown etiology or failure to thrive may be the only manifestation of underling renal disease [1].

The possibility of renal disease should be suspected in the differential diagnosis of any child with acute or chronic symptoms [2]. The aim of this study is to describe the current spectrum of pediatric renal diseases for the patients admitted to Assiut University Children Hospital which is considered tertiary draining center for all governates of Upper Egypt.

\section{Patients and Methods}

This observational descriptive study was carried out on children and adolescencts with age range from 1 day to 18 years who were admitted at Assiut University Children Hospital from November 2016 to October 2017, Data of the patients, including patients' presenting symptoms, examination findings, and laboratory investigation results. Statistical Analysis The data were tested for normality using the Anderson-Darling test and for homogeneity variances prior to further statistical analysis. Categorical variables were described by number and percent $(\mathrm{N}, \%)$, Chi-square test and fisher exact test used to compare between categorical variables. A two-tailed $\mathrm{p}<0.05$ was considered statistically significant. All analyses were performed with the IBM SPSS 20.0 software.

Inclusion criteria All newly diagnosed cases with renal disorders from birth to 18 years of age were included in the study.

Exclusion criteria Previously diagnosed cases, Outpatient visit at nephrology clinic was not included in this study and Patients with incomplete data.

\section{Results}

The total number of patients admitted to the hospital during the study period was 42048 so renal diseases represented $1.15 \%(482 / 42048)$ of the whole number of admissions. Over a period of one year duration, there were 482 patients with renal diseases admitted to Children Hospital. Out of 482 patients diagnosed with renal diseases (246/482) were male and (236/482) were female, the most common age group was from 1-5 year (table1). After exclusion of in complete data, case records were analyzed and categorized into: Acute Kidney Injury (AKI) due to prerenal causes, glomerulonephritis (GN), nephrotic syndrome (NS), congenital anomalies of kidney and urinary tract (CAKUT), urolithiasis, hemolytic uremic syndrome (HUS), tubular disorder as (RTA), urinary tract infection (UTI) not associated with renal disease, chronic kidney disease (CKD) due to unknown cause, diabetic nephropathy (DN) (table 2)

Table 1: Age and Gender distribution among the studied cases.

\begin{tabular}{|c|c|c|c|c|c|c|c|}
\hline \multirow{3}{*}{ Age } & \multirow{3}{*}{ Total number } & \multicolumn{5}{|c|}{ Gender } & \multirow{3}{*}{ Total percent $\%$} \\
\hline & & \multicolumn{2}{|c|}{ Male } & \multicolumn{2}{|c|}{ Female } & \multirow{2}{*}{ P. value } & \\
\hline & & Number & $\%$ & Number & $\%$ & & \\
\hline Birth - 1month & 66 & 42 & $63.6 \%$ & 24 & $36.4 \%$ & $0.003^{* *}$ & $13.7 \%$ \\
\hline 1month -12month & 123 & 44 & $35.8 \%$ & 79 & $64.2 \%$ & $<0.001 * *$ & $25.5 \%$ \\
\hline 1-5 year & 128 & 75 & $58.6 \%$ & 53 & $41.4 \%$ & $0.009 * *$ & $26.6 \%$ \\
\hline 5-10 year & 82 & 47 & $57.3 \%$ & 35 & $42.7 \%$ & 0.087 & $17 \%$ \\
\hline 10-17 year & 83 & 38 & $45.8 \%$ & 45 & $54.2 \%$ & 0.354 & $17.2 \%$ \\
\hline Total & 482 & 246 & $51 \%$ & 236 & $49 \%$ & 0.578 & $100 \%$ \\
\hline
\end{tabular}

Chi-square test,

* Statistically significant difference $(\mathrm{p}<0.05)$, ** highly statistically significant difference $(\mathrm{p}<0.01)$. 
As regard glomerulonephritis, the most affected age group was $(5-10)$ years with 43 female and

30 male patients .40 out of 182 patients were diagnosed as Post infectious glomerulonephritis. Lupus nephritis was seen in 24 patients, 21 female and 3 male patients. Rapidly progressive glomerulonephritis was seen in 8 patients and HSP was seen in 1 patient. Nephrotic syndrome was seen (71/182) patients. The most common presenting feature was edema, common affected age group was ( 1 - 5 year). Nephrotic syndrome was seen in 29 female and 42 male patients. Among the patients of Nephrotic syndrome, 90\% were steroid responsive and $10 \%$ were steroid resistant, 3 patients developed chronic kidney disease, 6 patients died from infection and hypovolemia. Out of 71 patients included in this study, renal biopsy was indicated in 12 patients due to unusual presentation of nephrotic syndrome and poor response to steroid, it was done only for 6 patients that revealed 4 patients with minimal change disease (MCD) and 2 patient with focal segmental glomerulosclerosis (FSGS). Among the patients of nephrotic syndrome, $90 \%$ were steroid responsive and $10 \%$ were steroid resistant, 3 patients developed chronic kidney disease, 6 patients died from infection and hypovolemia (table 3).

Table 2: Pattern of renal diseases in the studied patients.

\begin{tabular}{|c|c|c|}
\hline Type of renal disease & Number & Percentage \% \\
\hline Acute Kidney Injury due to prerenal \& causes & 143 & $29.7 \%$ \\
\hline Glomerulonephritis & 73 & $15.1 \%$ \\
\hline Nephrotic syndrome & 71 & $14.7 \%$ \\
\hline congenital anomalies & 68 & $14.1 \%$ \\
\hline Urolithiasis & 32 & $6.6 \%$ \\
\hline Hemolytic uremic syndrome & 27 & $5.6 \%$ \\
\hline Tubular disorder & 24 & $5 \%$ \\
\hline Urinary Tract Infection not associated with renal disease & 20 & $4.1 \%$ \\
\hline Chronic Kidney Disease due to unknown cause & 13 & $2.7 \%$ \\
\hline Diabetic nephropathy & 11 & $2.3 \%$ \\
\hline Total & 482 & $100 \%$ \\
\hline
\end{tabular}

Table 3: Types and percentage of glomerular diseases in the studied cases.

\begin{tabular}{|c|c|c|c|c|c|c|}
\hline \multirow{2}{*}{ Glomerular diseases } & \multirow{2}{*}{ Number } & Percentage & Female & \multicolumn{2}{c|}{ Male } \\
\cline { 3 - 7 } & & & & $\%$ & $(n)$ & \\
\hline Glomerulonephritis & 73 & $40 \%$ & 3 & $58.9 \%$ & 30 & $41.1 \%$ \\
\hline Nephrotic Syndrome & 71 & $39 \%$ & 29 & $40.8 \%$ & 42 & $59.2 \%$ \\
\hline Hemolytic uremic syndrome & 27 & $15 \%$ & 11 & $40.7 \%$ & 16 & $59.3 \%$ \\
\hline Diabetic nephropathy & 11 & $\%$ & 7 & $63.6 \%$ & 4 & $36.4 \%$ \\
\hline Total & 182 & $100 \%$ & 90 & $9.5 \%$ & 92 & $50.5 \%$ \\
\hline
\end{tabular}


Hemolytic uremic syndrome occurred in 27 patients, 11 female and 16 male. Main presenting feature was bloody diarrhea followed by oliguria and rising renal chemistry. Out of 27 patients diagnosed as hemolytic uremic syndrome, 10 patients died, 10 patients improved while progression into chronic kidney disease was seen in 7 patients. Diabetic nephropathy was seen in 11 patient as a result of poor control of hyperglycemia, common affected age group was more than 10 years. 10 patients were found to have micro proteinuria and 1 patient had chronic kidney disease.

Tubular disease was seen in 24 patients, 14 male and 10 female the main presenting feature was polyuria and polydipsia then growth failure. Main affected age group was ( 1 month - 12 month). 14 patients with appropriate treatment catch normal growth, 8 patients died from dehydration and 4 patients developed chronic kidney disease. Congenital anomalies of the kidney and urinary tract they were seen in 68 patients, $60 \%$ of them diagnosed antenatally (table 4). Acute kidney injury was diagnosed according to PRIFLE criteria. AKI was seen in 227 patients119 male and 108 female the most common affected group was (1 -5) year.AKI classified according to the cause prerenal, renal and post renal (table5). It was the most common renal disease in children admitted during the study period.It represents $47.1 \%$ of totally diagnosed renal diseases

The most common etiology was prerenal causes due to age and dehydration followed by sepsis. Chronic kidney disease was seen in 78 patients, most common age group was 10 - 18year. Of which 26 were females and 53 were male. The most common etiology of chronic kidney disease was congenital anomalies of kidney and urinary tract which had constituted $32 \%$ of patients with chronic kidney disease. Out of 78 patients with chronic kidney disease, 15 patients had ESRD and on regular hemodialysis.

Table 4: Pattern of congenital anomalies of the kidney and urinary tract in the studied cases.

\begin{tabular}{|c|c|c|}
\hline Congenital anomalies of the kidney and urinary tract & Number & Percentage \\
\hline Posterior urethral valve & 25 & $36.76 \%$ \\
\hline Polycystic kidney disease & 10 & $14.71 \%$ \\
\hline Multicystic dysplastic kidney & 4 & $5.88 \%$ \\
\hline Vesicouretric reflux(VUR) & 3 & $14.71 \%$ \\
\hline Renal agenesis / renal hypoplasia & 10 & $8.82 \%$ \\
\hline Pelviuretric junction obstruction (PUJ) & 6 & $4.41 \%$ \\
\hline Megaureter & 3 & $8.82 \%$ \\
\hline Ectopic kidney & 6 & $1.47 \%$ \\
\hline Horse shoe kidney & 1 & $100.00 \%$ \\
\hline Total & 68 & \\
\hline
\end{tabular}

Table 5: Etiology of acute kidney injury in the studied cases.

\begin{tabular}{|c|c|c|}
\hline \multicolumn{1}{|c|}{ Type } & Etiology & Number of patients \\
\hline \multirow{2}{*}{ Prerenal Failure } & Decreased intravascular volume\& sepsis & 143 \\
\hline \multirow{3}{*}{ Intrinsic renal disease } & Glomerulonephritis-RPGN & 30 \\
\cline { 2 - 4 } & Hemolytic uremic syndrome & 27 \\
\cline { 2 - 4 } Obstructive uropathy & Drug induced & 14 \\
\cline { 2 - 4 } & posterior urethral valve & 2 \\
\cline { 2 - 4 } & bilateral ureteropelvic junction obstruction & 10 \\
\hline
\end{tabular}


Table 6: Etiology of chronic kidney disease in the studied cases.

\begin{tabular}{|c|c|c|}
\hline Etiology of chonic kidney disease & Number & Percentage \\
\hline Congenital anomalies of kidney and urinary tract & 25 & $32.10 \%$ \\
\hline Unknown & 13 & $16.70 \%$ \\
\hline Vesicouretric reflux(VUR) & 9 & $11.50 \%$ \\
\hline Urolithiasis & 8 & $10.30 \%$ \\
\hline Glomerulonephritis & 8 & $10.30 \%$ \\
\hline Hemolytic uremic syndrome & 7 & $9 \%$ \\
\hline Tubular disorder & 4 & $5.10 \%$ \\
\hline Nephrotic syndrome & 3 & $3.80 \%$ \\
\hline Diabetic nephropathy & 1 & $1.30 \%$ \\
\hline Total & 78 & $100 \%$ \\
\hline
\end{tabular}

\section{Discussion}

This study provides information about the pattern and outcomes of childhood renal diseases in atertiary care center Assuit University children Hospital. A total number of 42048 children were admitted during the study period, after exclusion of incomplete data, about 482 children had renal disease. Giving a prevalence rate of $1.15 \%$ of patients admitted to pediatric wards during study duration; this is in agreement with Ashraf et al., 2016 who found that the renal disorders had constituted $1.5 \%$ in Kashmiri. (3). There were $246(51 \%)$ boys and $236(49 \%)$ girls, the common admitted age group was (1-5) year. The most common renal disease requiring admission was Acute kidney injury, which was found in 227 (47)\% from 482 patients , comparing this finding with other studies, Ashraf et al., 2016 found that AKI was the most common renal disease represent $32 \%$ of total hospitalized patients [3].

In our study143 patients out of 227 diagnosed as AKI were due to pre-renal causes followed by glomerulonephritis, hemolytic uremic syndrome and obstructive uropathy were other causes of AKI ,this in contrast to the study conducted in Jordon where the most frequent cause of ARF was acute tubular necrosis in association with multiple organ dysfunction and antibiotic nephrotoxicity [4]. 182 patients were diagnosed as glomerular diseases, the most common glomerular disease was glomerulonephritis .It was seen in 73 patients (table3).

Glomerulonephritis was found to be the second common pediatric renal disease including 73 patients, APIGN occurred in 40patient diagnosed by hematuria macroscopic or microscopic, hypertension, transitory hypocomplementemia , the condition may be associated with renal and cardiac failure, incomparable to a study conducted in Nigeria post-infectious acute glomerulonephritis was the second most common renal disorder [5]. Lupus nephritis was seen in 24 patients diagnosed according to American Rheumatology Association Criteria for SLE [6]. there were 21 female and
3 male with female predominance, (female : male ratio was $9: 1)$, this in agreement with other published data where SLE is more prevalent in female (Bogdanović, 2004 ) [7]. Lupus nephritis was found in over the age of 10 years, manifestation include renal and extra renal manifestation, renal biopsy was performed in only 12 patient out of 24 showing mainly Class III and IV. However, half of these patients did not perform renal biopsy which is against Joint European League Against Rheumatism and European Renal Association-European Dialysis and Transplant Association (EULAR/ERA-EDTA) recommendations for the management of adult and pediatric lupus nephritis they recommend performance of renal biopsy when there is any sign of renal involvement in particular, urinary findings such as reproducible proteinuria $\geq 0.5 \mathrm{~g} / 24 \mathrm{~h}$ especially with glomerular hematuria and/or cellular casts - should be an indication for renal biopsy [8].

Hemolytic uremic syndrome was found in 27 patients. It was presented mainly with oliguria/anuria, 11 patient was found to have diabetic nephropathy. Nephrotic syndrome was found in 71 patients, $90 \%$ were steroid responsive and $10 \%$ were steroid resistant this in agreement with (Hodson et al., 2007)who found that the majority of children with NS respond to corticosteroids [9]. Congenital anomalies of the kidney and urinary tract was found in 68 patients , 60\% diagnosed antenatal, posterior urethral valve was the most common detected anomaly, early intervention needed to preserve kidney function. Chronic kidney disease was found in 78 patients accounting for $16 \%$ of totally diagnosed patients with renal disease, this is in agreement with (Kari, 2006), who found that congenital anomalies of the kidney and urinary tract was the main cause of

CRF in Saudi [10] However, our study in contrast to studies from Sudan and Nigeria where chronic glomerulonephritis was the main cause of CRF (Ali et al., 2012), (Anochie and Eke, 2003) [11, 12]. 
Others causes of CDK were vesicouretric reflux, glomerulonephritis, urolithiasis, HUS and nephrotic syndrome .The cause of CKD couldn't be detected in 13 patients.

\section{Conclusion}

Acute kidney injury (AKI) due to pre-renal cause was the most common renal disease among diagnosed patients followed by glomerulonephritis as most cases with AKI caused by prerenal causes. Adequate assessment of volume status of critically ill patients with early interference can improve patient outcome. Antenatal screening for congenital anomalies of the kidney and urinary tract can prevent development of chronic kidney disease for correctable anomalies.

\section{Abbreviations}

AKI: Acute kidney injury.

GN: Glomerulonephritis.

NS: Nephrotic Syndrome.

HUS: Hemolytic uremic syndrome.

UTI: Urinary tract infection.

CAKUT: Congenital anomalies of the kidney and urinary tract.

CKD: Chronic kidney disease.

DN: Diabetic nephropathy.

PIGN: Postinfectious glomerulonephritis.

RPGN: Rapidly progressive glomerulonephritis.

HSP: Henoch-Schonlein purpura.

MCD: Minimal change disease

FSGS: Focal segmental glomerulosclerosis

\section{References}

1. Bhatta N, Shrestha P, Budhathoki S, Kalakheti B, Poudel P, Sinha A, et al. Profile of renal diseases in Nepalese children. 2008.

2. Shenoy MA, Webb NJA. Clinical Evaluation of the Child with Suspected Renal Disease. In: Avner ED,

\section{Declaration}

\section{Ethics approval and consent to participate}

This study protocol and the consents were approved and deemed sufficient by Ethical Committee of Pediatric Department, Faculty of Medicine, Assiut University. And informed written consent was obtained in every case from their legal guardians.

\section{Funding}

The authors declare that they didn't receive any financial support from agencies or others.

\section{Conflict of interest \\ No}

\section{Acknowledgements}

We would like to thank all patients and their family members for their valuable contributions to the study.
Harmon WE, Niaudet P, Yoshikawa N, Emma F, Goldstein SL, editors. Pediatr Nephrol. Berlin, Heidelberg: Springer Berlin Heidelberg; 2016. p. 595-612.

3. Ashraf M, Kumar V, Bano RA, Wani KA, Ahmed J, Ahmed K. Spectrum of Renal and Urinary Tract Diseases in Kashmiri Children. Journal of clinical and diagnostic research: JCDR. 2016;10(6):SM01.

4. Akl K. Pediatric nephrology consultations in a tertiary academic center in Jordan. Saudi Journal of Kidney Diseases and Transplantation. 2008;19(3):456.

5. Onifade E. A ten-year review of childhood renal admissions into the Lagos University Teaching Hospital, Nigeria. Nigerian Quarterly Journal of Hospital Medicine. 2003;13(3-4):1-5.

6. Bitzan M. Glomerular Diseases. In: Phadke KD, Goodyer P, Bitzan M, editors. Manual of Pediatric Nephrology. Berlin, Heidelberg: Springer Berlin Heidelberg; 2014. p. 141-229.

7. Marks SD, Tullus K. Lupus Nephritis. In: Geary DF, Schaefer F, editors. Pediatric Kidney Disease. Berlin, Heidelberg: Springer Berlin Heidelberg; 2016. p. 759-80.

8. Bertsias GK, Tektonidou M, Amoura Z, Aringer M, Bajema I, Berden JHM, et al. Joint European League Against Rheumatism and European Renal AssociationEuropean Dialysis and Transplant Association (EULAR/ERA-EDTA) recommendations for the management of adult and paediatric lupus nephritis. Annals of the Rheumatic Diseases. 2012.

9. Hodson EM, Willis NS, Craig JC. Corticosteroid therapy for nephrotic syndrome in children. Cochrane Database Syst Rev. 2007;4.

10. Kari J. Chronic renal failure in children in the western area of Saudi Arabia. Saudi Journal of Kidney Diseases and Transplantation. 2006;17(1).

11. Ali ELTMA, Rahman AHA, Karrar ZA. Pattern and outcome of renal diseases in hospitalized children in Khartoum State, Sudan. Sudanese Journal of Paediatrics. 2012;12(2):52-9.

12. Anochie I, Eke F. Chronic renal failure in children: a report from Port Harcourt, Nigeria (1985-2000). Pediatr Nephrol. 2003;18(7):692-5. 